Rev. Saúde públ., S. Paulo 15:321-37, 1981

\title{
STAPHYLOCOCCUS AUREUS ENTEROTOXIGENICO EM DOCES CREMOSOS VENDIDOS EM PADARIAS E CONFEITARIAS DO MUNICIPIO DE SÃO PAULO, BRASIL *
}

Sebastiâo Timo laria **

IARIA, S.T. Staphylococcus aureus enterotoxigênico em doces cremosos vendidos em padarias e confeitarias do municipio de São Paulo, Brasil. Rev. Saude públ., S. Paulo, 15:321-37, 1981.

RESUMO: A partir de 100 amostras de doces cremosos coletados em 40 padarias e confeitarias da cidade de São Paulo (Brasil), foi realizada a contagem de $\mathbf{S}$. aureus por grama de alimento. As cepas isoladas, após terem sido identificadas morfológica e bioquimicamente, foram submetidas a provas de fagotipagem e à verificação da capacidade produtora de enterotoxina. Das 100 amostras de doces examinadas, $38,0 \%$ foram positivas para $\mathbf{S}$. aureus e originárias de $21(52,5 \%)$ dos 40 estabelecimentos visitados. Do total de doces analisados, $7 \%$ foram positivos para cepas enterotoxigênicas sendo $5 \%$ do tipo C, $1 \%$ do $\mathrm{B}$ e $1 \%$ do $\mathrm{D}$. das 76 cepas isoladas de $\mathrm{S}$. aureus, $39(51,5 \%)$ revelaram-se não fagotipáveis. Das fatotipáveis houve predominância das que foram lisadas por fagos do grupo I isoladamente $(21,2 \%)$ ou em associação com fagos de outros grupos $(35,5 \%)$. Cepas não tipáveis de $\mathbf{S}$. aureus estavam presentes em $76,2 \%$ dos estabelecimentos em que houve amostras positivas para esta bactéria.

UNITERMOS: Staphylococcus aureus. Enterotoxina. Intoxicação alimentar estafilocócica.

\section{INTRODUCAAO}

O Staphylococcus aureus constitui uma espécie bacteriana cuja importância na patologia humana e animal é muito conhecida. No homem, além de ocasionar infecções, que podem variar de pequenos furúnculos na pele até a septicemia grave com focos metastáticos ${ }^{63}$, produz freqüentemente infecções assintomáticas 1.i2.

Muitos estudos foram realizados com o objetivo de verificar taxas de portadores de S. aureus. Assim, em pessoas assintomáticas tem-se constatado taxas de portadores nasais variando de 30 a $60 \%$. $\mathrm{Na}$ garganta, em vários estudos realizados, foram constatadas proporções de portadores de 4 a $64 \%$, e nas mãos de aproximadamente, 40 a $47 \%$. A este respeito, segundo Zelante $7 *(1974)$ as pesquisas têm mostrado que os portadores de $S$. aureus na boca

* Parte da Tese de Livre Docência apresentada ao Departamento de Microbiologia e Imuno ogia do Instituto de Ciências Biomédicas da USP, 1978, subordinada ao título: "Staphylococcus aureus em doces vendidos em padarias e confeitarias do município de São Paulo: produção de enterotoxina estafilocócica e fagotipagem a partir das cepas isoladas (1975/76).

** Do Departamento de Microbiologia e Imunologia do Instituto de Ciências Biomédicas da USP "Setor Saúde Pública", Laboratório de Microbiologia de Alimentos - Av. Dr. Arnaldo, 715 - 01255 - São Paulo, SP - Brasil. 
IARIA, S.T. Staphylococcus aureus enterotoxigênica en doces cremosos rendidos em padarias e confeitarias do municipio de São Paulo. Brasil. Rer. Sứde públ., S. Paulo, 15:321-37, 1981.

são fontes de infecção tão importantes quanto os portadores nasais.

A partir de portadores de $S$. aureus pode, por vários mecanismos, atingir o ambiente, as vestimentas, o mobiliário, os utensílios e os equipamentos, assim como os alimentos, direta ou indiretamente. Deve-se anda considerar que os animais domésticos também podem albergar $O S$. aureus ${ }^{5 *}$, constituindo-se em possiveis fontes de contaminação de alimentos.

Em alimentos, segundo Ingram ${ }^{4:}$ (1960), é relevante a contagem alta de cocos Gram-positivos, dispostos em cachos, mesófilos, catalase-positivos, anaeróbios facultativos, quaisquer que sejam, pois indica que podem estar presentes também cepas de $S$. aureus em grande número. Por outro lado, a presença de $S$. aureus em um alimento pode ser interpretada como indicadora de contaminação a partir de fossas nasais, boca $e$ pele de manipuladores i:

De forma geral, alimentos como carne e derivados, aves, leite e derivados, pescado, verduras e outros, mostram-se freqüentemente contaminados com $S$. aureus $\$$,

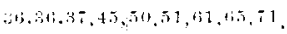

Estando presente em alimento e havendo condições favoráveis à sua multiplicação, o $S$. aureus pode, em algumas horas, atingir números elevados. Por outro lado, dependendo da cepa pode haver, durande o período de multiplicação, produção de enterotoxina, que é uma exotoxina termoestável e responsável pela intoxicaçāo alimentar estafilocócica.

Atualmente tem-se conhecimento de grande variedade de alimentos já envolvidos em surtos desta intoxicação, tais como carne bovina, carne seca, frango congelado e cozido, lagosta, camarão, caranguejo, peixe, lingua, presunto, tortas de presunto e de carne de coelho, leite, queijo, creme de leite, sorvete, produtos cárneos embutidos, molho de frango e holandês. Produtos de confeitaria recheados com creme natural ou artificial, como bolos, bombas, roscas, tortas e fo-
Thados, têm sido também relacionados a surtos de intoxicação alimentar estafilocócica $11,17,22,23,32,34,41,44,48,62,69$.

Alguns pesquisadores $29,30.31$ constataram que todas as cepas de estafilococos produtores de enterotoxina, por eles estudadas, eram coagulase-positivas e que nem todas as cepas coagulase-positivas eram enterotoxigênicas. Tem-se, contudo, isolado cepas de estafilococos coagulase-negativas produtoras de enterotoxina 8.2.2. Entretanto, parece não haver relação entre a produção de enterotoxina a de outras toxinas ou fatores de virulência elaborados pelo $S$. aureus (Angelotti 1, 1969).

De há muito vêm sendo realizados estudos com o objetivo de relacionar a produção de enterotoxina estafilocócica ao tipo de $S$. aureus, determinado através da fagotipagem. A este respeito, tem sido mostrado que a maioria das cepas de $S$, aureus, associadas a surtos de intoxicação alimentar, são lisadas por fagos do grupo lll e mais raramente de outros grupos 51.54.in. Mais recentemente, na Inglaterra, Sinkovicova e Gilbert (1971), Gilbert e Wieneke 3\% (1973) e Wieneke ${ }^{69}$ (1974), verificaram que as cepas de $S$. aureus implicadas em surtos de intoxicaçāo alimentar são, na maioria das vezes, lisadas por fagos do grupo lll ou I/Ill e, em menor numero, dos grupos II e IV. Entretanto, a partir da fagotipagem, não se pode predizer se uma determinada cepa de $S$. aureus é ou não capaz de produzir enterotoxina estafilocócica 1,35. Assim, no diagnóstico de um surto de intoxicação alimentar estafilocócica, o ideal é a verificação da presença de enterotoxina nos alimentos suspeitos (Dack 22, 1964).

Até há alguns anos, a pesquisa de enterotoxina era feita ministrando-se a voluntários humanos ${ }^{22}$, macacos 24,47,3 ou gatos jovens $2 \pi, 5 s$ os próprios alimentos implicados em surtos ou sobrenadante de culturas de $S$. aureus isoladas a partir deles.

Posteriormente, os estudos sobre purificação e antigenicidade da enterotoxina estafilocócica permitiram o uso de técnicas 
IARIA, S.T. Staphylococcus aureus enterotoxigênico em doces cremosos vendidos em padarias e confeitarias do municipio de São Paulo, Brasil, Rev. Saúde públ., S. Paulo, 15:321-37, 1981.

sorológicas na detecção dessa toxina em sobrenadantes de culturas de $S$. aureus, obtidas por diferentes métodos (Casman e Bennett ${ }^{13}$, 1963; Hallander ${ }^{39}$, 1965 e Donnelly e col.28, 1967) ou em extratos obtidos a partir de alimentos (Hall e col.38, 1963; Casman e Bennett 14, 1965 e Read e col.56,5;, 1965).

São conhecidos, atualmente, cinco tipos de enterotoxina estafilocócica denominadas $A$ (Casman e col.15, 1963), $B$ (Bergdoll e col. $^{y}$, 1959), $C$ (Bergdoll e col., 1965$), D$ (Casman e col.16, 1957) e $E$ (Bergdoll e col. ${ }^{6}$, 1971).

Dentre os métodos sorológicos de pesquisa de enterotoxina estafilocócica desenvolvidos, até o presente, devem-se ressaltar os de imunofluorescência 33,34.4", inibição da hemaglutinação $12.46,53,59$, difusão simples em ágar ${ }^{*}$, radioimunoensaio em fase sólida ${ }^{4}$. 18.19 e o da dupla imunodifusão de Oakley em tubo ou de Ouchterlony em placas (Gilbert $3 \overline{5}, 1974$ ). Segundo este autor 35 , as técnicas mais utilizadas são as de dupla imunodifusāo em ágar em lâmina de Wadsworth is (1957) e de Crowle 21 (1958).

No Brasil, há um numero muito reduzido de investigações relativas a $S$. aureus enterotoxigênico. Assim, Cotillo:" (1967) estudou o efeito da penicilina e da estreptomicina sobre a síntese de enterotoxina. Delazari e Leitão 25 (1976) procederam a contagem de $S$. aureus em macarrão, verificando que $69,5 \%$ das amostras examinadas eram positivas para essa bactéria; as contagens variaram de 10 a $10^{4} / \mathrm{g}$ de alimento. Das 106 cepas de $S$. aureus isoladas, $67(63,0 \%)$ revelaram-se enterotoxigênicas. Iaria e col.42 (1980), estudaram a ocorrência de $S$. aureus nas fossas nasais de manipuladores de alimentos em cozinhas de hospitais. De 34 individuos examinados, $12(35,3 \%)$ revelaram-se portadores de $S$. aureus dos quais $2(16,7 \%)$ foram positivos para cepas produtoras de enterotoxina estafilocócica.

Do exposto e, tendo em vista a falta, em nosso pais, de investigações sobre fre- qüência de $S$. aureus enterotoxigênico a partir de alimentos, planejou-se a presente pesquisa que tem por finalidade determinar a presença e número de $S$. aureus em doces cremosos vendidos em padarias e confeitarias do município de São Paulo; verificar a capacidade produtora dos diferentes tipos de enterotoxina estafilocócica das cepas isoladas; e determinar os fagótipos de tais cepas, produtoras ou nāo de enterotoxina.

\section{MATERIAL E MÉTODOS}

Obtençāo das amostras de doces cremosos - De 40 padarias e confeitarias localizadas no município de São Paulo foram adquiridas 100 unidades de doces expostos à venda para consumo, na quase totalidade sem refrigeração. $O$ conjunto de amostras estudadas, coletadas no período de novembro de 1975 a novembro de 1976, era constituído de diferentes tipos de doces de consistência cremosa ou contendo creme natural (creme de chantili) ou artificial, de cobertura e/ou de recheio assim distribuidos: bombas (36 unidades), bolos fatiados (17), tolhados (13), sonhos (13), pudins (5), tortas (5), bombocados (4), pães doces com creme (4) e quindim (3).

Logo após a sua obtenção, as amostras eram transportadas, o mais rapidamente possivel, ao laboratórjo e mantidas em geladeira a $4^{\circ} \mathrm{C}$ até $o$ início do exame. O tempo decorrido entre a coleta das amostras e 0 início da análise foi no máximo, de uma hora.

Preparo das amostras $e$ de suas diluições - De cada amostra foram pesados, assépticamente, $11 \mathrm{~g}$ de creme de recheio e/ou de cobertura em frasco esterilizado de 250 $\mathrm{ml}$, redondo, de boca larga, com tampa de vidro esmerilhado e contendo pérolas de vidro. A seguir, foram adicionados $90 \mathrm{ml}$ de água fosfatada estéril, $\mathrm{pH} 7,2$, a fim de se obter uma diluição inicial do creme a $10^{-1}$ (Thatcher e Clark ${ }^{67}, 1973$ ). Quando o creme era artificial procedia-se, a seguir, a sua homogeneização por agitação manual vigorosa do frasco. Tratando-se de creme 
IARIA, S.T. Staphylococcus aureus enterotoxigénico em doces cremosos vendidos em padarias e confeitarias do município de São Paulo, Brasil. Rev. Saúde públ., S. Paulo, 15:321-37, 1981.

natural, antes da agitação a mistura era aquecida a $40^{\circ} \mathrm{C}$ a fim de se obter a fusão do creme. No caso dos doces de consistência cremosa, o preparo da amostra e a diluição inicial eram realizados da mesma forma, porém a partir de $11 \mathrm{~g}$ do produto.

$\mathrm{Da}$ diluição inicial, preparava-se uma série de diluiçóes decimais do creme, de

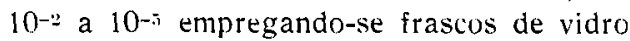
com rolhas de borracha, contendo $9 \mathrm{ml} d e$ água fosfatada, pH 7,2 esterilizada.

Contagem, isolamento $e$ identificaçōo de Staphylococcus aureus - $\mathrm{Na}$ semeadura inicial, $0,2 \mathrm{ml}$ de cada diluição do material $\left(10^{-1}\right.$ a $\left.10^{-5}\right)$ era depositado na superficie de ágar Baird-Parker (Merck) em placas. $O$ inóculo era espalhado em todo a superfície do meio por intermédio de um bastão de vidro em "L" esterilizado e, em seguida, as placas eram incubadas em estufa a $37^{\circ} \mathrm{C}$ por 24-48 horas (Thatcher e Clark ${ }^{67}$, 1973).

Após a incubação procedia-se, nas placas com 30 a 300 colônias, a contagem das de cor negra, brilhantes, com zona de precipitação em toda a sua borda e circundada por um halo claro: $O$ cálculo presuntivo do número de $S$. aureus por grama do material examinado era feito, multiplicando-se por 5 o número de colônias contadas e, a seguir, multiplicando-se o resultado pela recíproca da diluição correspondente à placa de contagem. A confirmação desse resultado ou a sua correção era feita após a identificação das cepas referentes às colônias isoladas. A seguir, da placa de contagem procedia-se $o$ isolamento de colônias, cujo número variou de um a cinco e, cada uma delas era semeada em um tubo de ágar simples inclinado e este incubado a $37^{\circ} \mathrm{C}$ por $24 \mathrm{~h}$.

A partir das culturas em ágar simples inclinado, preparavam-se esfregaços em lâminas, corados pelo método de Gram, para a verificação microscópica da morfologia das bactérias isoladas. Em seguida, par- tindo-se dessas mesmas culturas, as cepas isoladas eram submetidas às provas da catalase:", da oxidação e fermentação da glicose $(\mathrm{F} / \mathrm{O})^{66}$, da coagulase ${ }^{64}$ e da desoxirribonuclease (DNase) 26 .

Fagotipagem - A caracterização dos tagótipos das cepas isoladas de $S$. aureus foi realizada na Seção de Fagotipagem do Laboratório de Estreptococos e Estafilococos do Departamento de Parasitologia, Microbiologia e Imunologia da Faculdade de Medicina de Ribeirão Preto, da Universidade de São Paulo, sendo a metodologia adotada a proposta por Blair e Williams 10 (1961). Nas provas foram utilizados 23 fagos do conjunto básico internacional (Solé-Vernin ${ }^{61}$, 1976), 7 experimentais (fagos $86,88,89,90$, 92,D11 e HK2) e dois extras (187 e 42 D). Todas as cepas isoladas de $S$. aureus foram submetidas à ação de $1 \times$ RTD ("Routine Test Dose") de cada cepa de bacteriófago e quando não reagiam a esta dose, procedia-se à prova com 100xRTD (Solé-Vernin $\left.{ }^{i t}, 1976\right)$.

Pesquisa da produção de enterotoxina pelas cepas isoladas - $\mathrm{Na}$ produção de enterotoxina pelas cepas isoladas, foi empregada a técnica da cultura de $S$. aureus em saco de celofane, preconizada por Donnelly e col.is (1967), com base no estudo realizado por Simkovicova e Gilbert $6:$ (1971). Na verificação da presença de enterotoxina nos extratos obtidos, a partir das culturas das cepas estudadas, foi empregada a técnica da dupla imunodifusão em ágar em lâminas (Siles-Villarroel 60, 1972), sendo utilizados como padrōes as enterotoxinas $A, B, C, D$ e $E$ e as respectivas anti-enterotoxinas."

\section{RESULTADOS}

$\mathrm{Na}$ Tabela 1 encontra-se a distribuição das amostras de doces examinadas, segundo a positividade para $S$. aureus e o tipo de

\footnotetext{
* Preparadas e gentilmente fornecidas pelo Professor Merllin S. Bergdoll do "Food Research Institute" da Universidade de Wisconsin. EUA.
} 
IARIA, S.T. Staphylococcus aureus enterotoxigênico em doces cremosos vendidos em padarias e confeitarias do município de São Paulo, Brasil, Rev. Saúde públ., S. Paulo, 15:321-37, 1981.

enterotoxina estafilocócica produzida a partir das cepas isoladas. Das 100 amostras pesquisadas, $38,0 \%$ revelaram-se positivas para $S$. aureus, dos quais $7(18,4 \%)$ apresentaram-se com cepas produtoras de enterotoxina estafilocócica.

$\mathrm{Na}$ Tabela 2 constam as 40 padarias e confeitarias das quais foram obtidos os alimentos estudados, conforme a positividade para $S$. aureus em doces nelas expostos è. venda para consumo e o tipo de enterotoxina estafilocócica elaborada por cepas deles isoladas. A presença de $S$. aureus foi verificada em $21(52,5 \%)$ desses estabelecimentos comerciais. Dos 21 , em $7(33,3 \%)$ encontraram-se amostras com cepas produtoras de enterotoxina estafilocócica.

T'A B E L A 1 .

Amostras de doces examinadas segundo a positividade para $S$. aureus e o tipo de enterotoxina produzida a partir das cepas isoladas (São Paulo. 1975/1976).

\begin{tabular}{|c|c|c|c|c|c|c|c|c|c|c|}
\hline \multirow{3}{*}{$\begin{array}{l}\text { Isolamento } \\
\text { de } \\
\text { S. aureus }\end{array}$} & \multirow{2}{*}{\multicolumn{2}{|c|}{ Doces }} & \multirow{2}{*}{\multicolumn{2}{|c|}{$\frac{\text { Doces }}{\text { Total }}$}} & \multirow{2}{*}{$S}$. & \multirow{2}{*}{$\frac{\text { aureus }}{\mathbf{B}}$} & \multirow{2}{*}{\multicolumn{2}{|c|}{ produtor de }} & \multirow{2}{*}{\multicolumn{2}{|c|}{$\frac{\text { enterotoxina }}{\mathrm{D}}$}} \\
\hline & & & & & & & & & & \\
\hline & No & $\%$ & No & $\%$ & $\mathrm{~N}^{i}$ & $\%$ & No & $\%$ & No & $\%$ \\
\hline Positivo & 38 & 38,0 & 7 & 18,4 & 1 & 2,6 & 5 & 13,2 & 1 & 2.6 \\
\hline Negativo & 62 & 62,0 & - & - & - & - & - & - & - & - \\
\hline Total & 100 & 100,0 & 7 & 7,0 & 1 & 1,0 & 5 & 5,0 & J & 1,0 \\
\hline
\end{tabular}

T A B E L A 2

Padarias e confeitarias segundo a positividade para $S$. aureus nas amostras de doces examinadas e tipo de enterotoxina produzida a partir das cepas isoladas (São Paulo, 1975/1976).

\begin{tabular}{|c|c|c|c|c|c|c|c|c|c|c|}
\hline \multirow{3}{*}{$\begin{array}{c}\text { Isolamento } \\
\text { de } \\
\text { S. aureus }\end{array}$} & \multirow{2}{*}{\multicolumn{2}{|c|}{$\begin{array}{c}\text { Padarias } \\
e \\
\text { Confeitarias }\end{array}$}} & \multicolumn{8}{|c|}{$\begin{array}{l}\text { os para s, aureus produ } \\
\text { enterotoxina }\end{array}$} \\
\hline & & & \multicolumn{2}{|c|}{ Total } & \multicolumn{2}{|c|}{$\mathbf{B}$} & \multicolumn{2}{|r|}{$\mathrm{C}$} & \multicolumn{2}{|c|}{ D } \\
\hline & $\mathrm{N}^{8}$ & $\%$ & No & $\%$ & $N^{0}$ & $\%$ & $\mathrm{Ne}$ & $\%$ & $\mathrm{~N}^{0}$ & $\%$ \\
\hline Positivo & 2.1 & 52,5 & 7 & 33,3 & 1 & 4,8 & 5 & 23,7 & 1 & 4.8 \\
\hline Negativo & 19 & 47,5 & - & - & - & - & - & - & - & - \\
\hline Total & 100 & 100,0 & 7 & 7,0 & 1 & 1,0 & 5 & 5,0 & 1 & 1.0 \\
\hline
\end{tabular}

$\mathrm{Na}$ Tabela 3 estão distribuídas as 38 amostras positivas dos diferentes tipos de doces examinados, segundo o número de bactérias por grama do material analisado. Os valores obtidos na contagem de $S$. aureus variaram de $5 \times 10$ a $30,5 \times 10^{\%} / \mathrm{g}$.

A Tabela 4 mostra a distribuição das amostras examinadas segundo a contagem de
S. aureus por grama de creme ou de doce de consistência cremosa e a presença de cepas produtoras de enterotoxina estafilocócica. Os valores foram distribuídos em oito classes, sendo a primeira $(0$ a $5 \times 10$ $S$. aureus $/ g$ ) a que encerra os resultados considerados negativos. Isto é devido ao processo de contagem usado, pois com ele, 
IARIA, S.T. Staphylococous aureus enterotoxigènico em doces cremosos vendidos em padarias e confeitarias do município de São Paulo, Bras:1, Rev. Saúde públ., S. Paulo, 15:321-37, 1981.

T A B E L A 3

Amostras de doces positivas para $\$$. aureus. segundo o número dessa bactéria por grama do material analisado (São Paulo, 1975/1976).

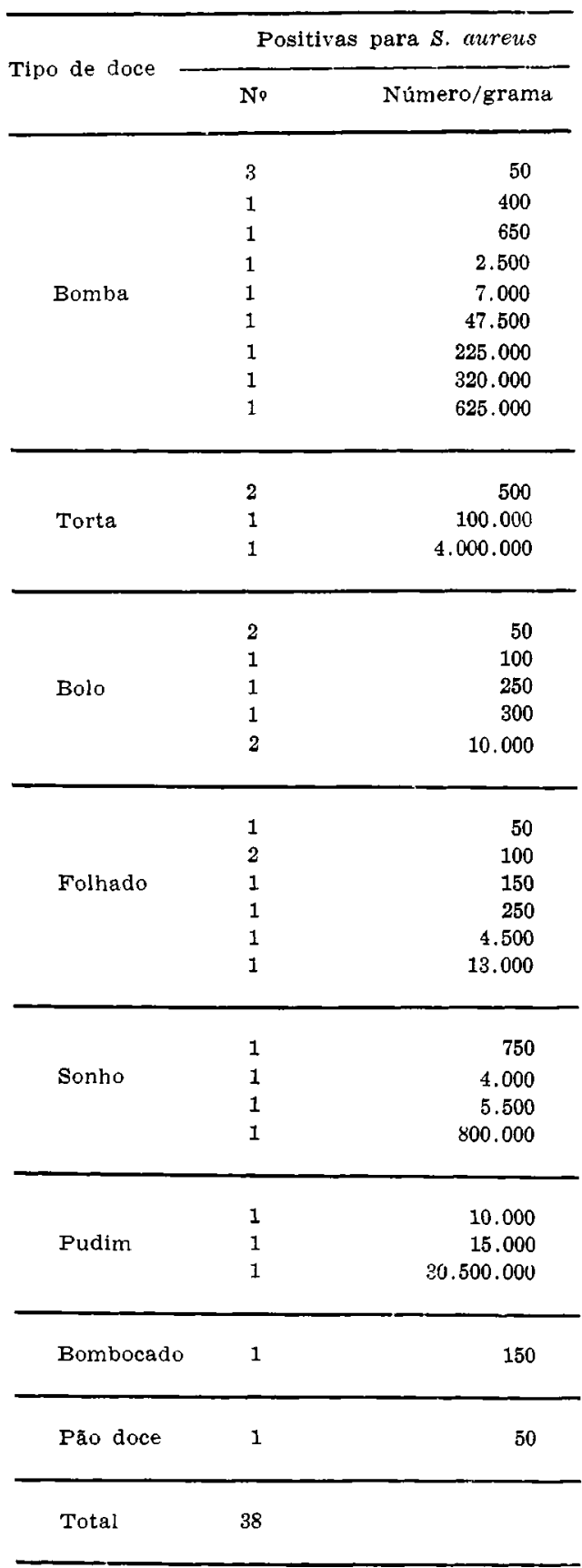

teoricamente, só se poderia obter crescimento de colônias de $S$. aureus, nas placas correspondentes à primeira diluição usada, quando o seu número fosse igual ou superior a $50 / \mathrm{g}$ do material analisado. Por essa razão, 62(62,0\%) amostras foram consideradas negativas. Com relação às amostras posititivas, as contagens de $S$. aureus, considerando-se as classes estabelecidas variaram entre $5 \times 10$ a $10^{\circ}$ e $10^{\circ}$ ou mais por grama co material examinado.

$\mathrm{Na}$ Tabela 5 encontra-se a distribuição dos valores relativos à contagem de $S$. aureus que é semelhante a da tabela anterior; entretanto, os percentuais das amostras de cada classe foram calculados em relação ao total de doces positivos para s. aureus. Outrossim os percentuais das amostras positivas para cepas enterotoxigênicas foram calculados considerando-se o total de amostras da classe correspondente.

$\mathrm{Na}$ Tabela 6 estão distribuídas as amostras estudadas, segundo o tipo de doce, a positividade para $S$. aureus e o tipo de enterotoxina elaborado pelas cepas isoladas. Do total de doces estudados, $36,0 \%$ eram constituidos por amostras de bombas das quais $11(30,6 \%)$ foram positivas para $S$. aureus; $35,0 \%$ foram tortas, bolos e folhados fatiados, com $18(51,4 \%)$ amostras positivas; $13(13,0 \%)$ foram sonhos, das quais $4(30,8 \%)$ mostraram-se positivas; $12(12,0 \%)$ vieram de pudins, bombocados e quindins, sendo $4(33,3 \%)$ positivas e, $4(4,0 \%)$ de pães doces com creme, dos quais um $(25,0 \%)$ foi positivo para $S$. aureus.

Das 18 amostras positivas para $S$. aureus, do conjunto composto por tortas, bolos e folhados, das 4 de sonhos e das 4 do grupo formado por pudins, bombocado e quindins, obteve-se o isolamento de cepas produtoras de enterotoxina de $4(11,4 \%), 1(7,7 \%)$ e $2(16,6 \%)$ respectivamente.

A Tabela 7 mostra a distribuição das cepas de $S$. aureus isoladas a partir das amostras examinadas, segundo o resultado da fagotipagem e a produção de enterotoxina. Do total das cepas, $39(51,5 \%)$ não 
AFIA. S.T. Staphylococciss aureus unterotoxige nico em doces cremosos vendidos em padarias confeitarias do municipio de São Puulo, Brasil, Ret. Soúde públ., S. Paulo, 15:321-37. 1981.

T A B E L A 4

Amostras de doces segundo o número de $\boldsymbol{S}$. aureus por grama do material examinado e a sua positividade para cepas enterotoxigênicas.

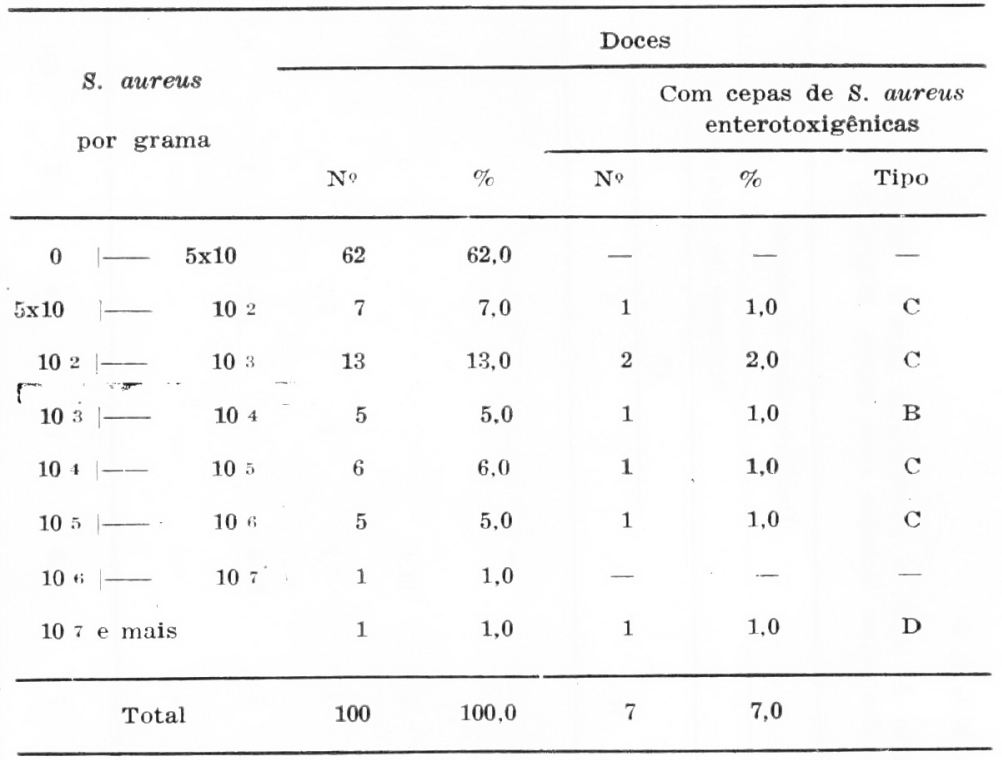

T A B E L A 5

Doces positivos para S. aureus segundo o número dessa bactéria por grama do material examinado e a positividade para cepas enterotoxigênicas.

\begin{tabular}{|c|c|c|c|c|c|c|c|}
\hline & & & \multicolumn{5}{|c|}{ Doces } \\
\hline \multirow{2}{*}{\multicolumn{3}{|c|}{$\begin{array}{l}\text { S. aureus } \\
\text { por grama }\end{array}$}} & \multirow[b]{2}{*}{ Ne } & \multirow[b]{2}{*}{$\%$} & \multicolumn{3}{|c|}{$\begin{array}{c}\text { Com cepas de S. aureus } \\
\text { enterotoxigênicas }\end{array}$} \\
\hline & & & & & $\mathrm{N}^{0}$ & $\%$ & Tipo \\
\hline $5 \times 10$ & - & $10=$ & 7 & 18,1 & 1 & 14,2 & $\mathrm{C}$ \\
\hline $10=$ & $-\cdots$ & 103 & 13 & 34,2 & 2 & 15,4 & C \\
\hline 103 & - & 104 & 5 & 13,2 & 1 & 20,0 & B \\
\hline 104 & - & 105 & 6 & 15,8 & 1 & 16,7 & C \\
\hline 105 & - & 10 & 5 & 13,1 & 1 & 20,0 & C \\
\hline 106 & - & 107 & 1 & 2,6 & - & - & - \\
\hline 107 & mais & & 1 & 2,6 & 1 & 100,0 & D \\
\hline & Total & & 38 & 100,0 & 7 & 18,4 & \\
\hline
\end{tabular}




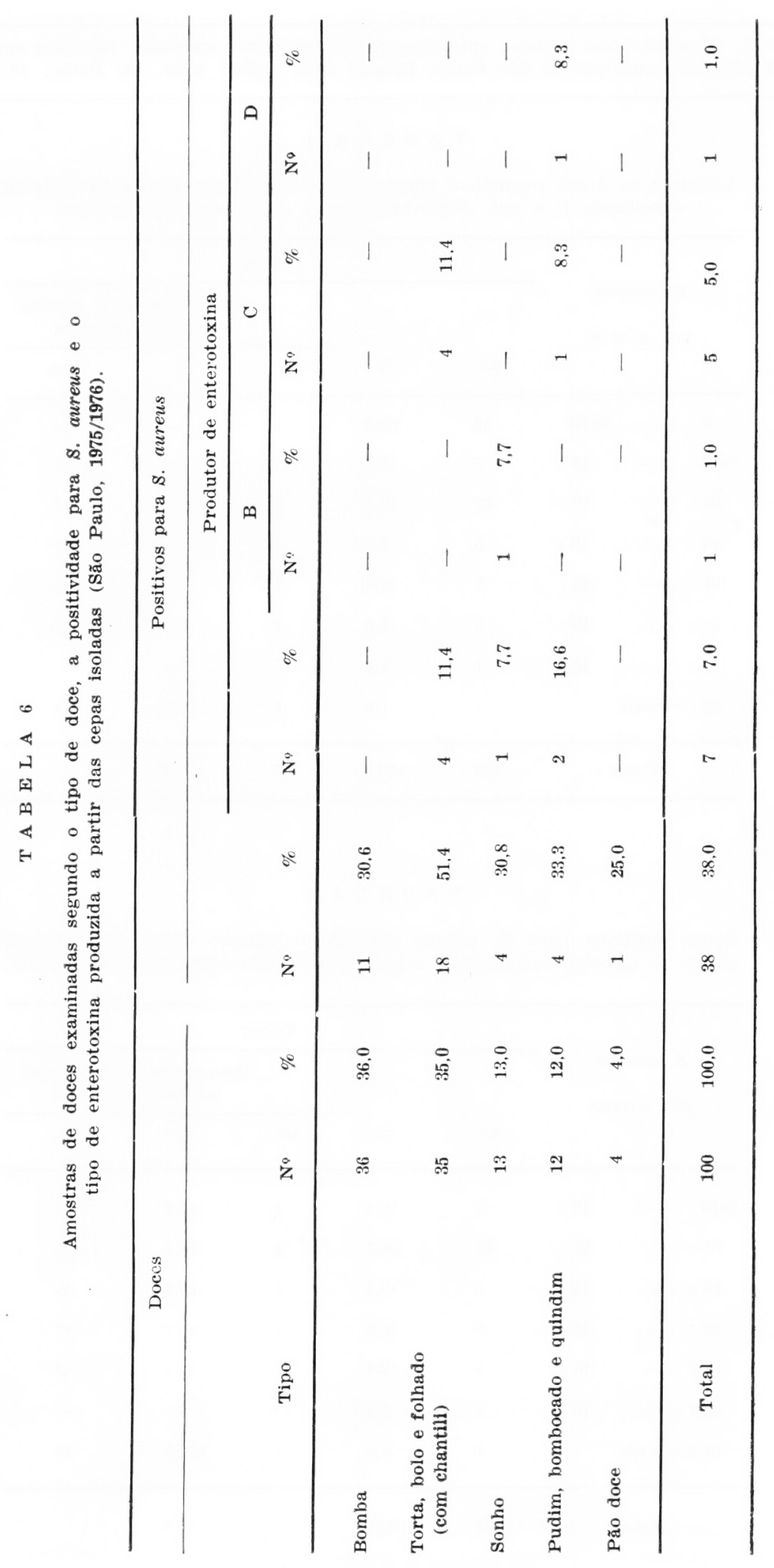


IARIA. S.T. Staphylococcus aureus enterotoxigênicc em doces cremosos vendidos em padarias $\theta$ confeitarias do municipio de São Paulo, Brasil, Rev. Saúde pübl., S. Paulo. 15:321-37, 1981.

T A B E L A 7

Cepas de $S$. aureus isoladas dos 38 doces positivos para essa bactéria, segundo a fagotipagem e a produção de enterotoxina (São Paulo, 1975/1976).

\begin{tabular}{|c|c|c|c|c|c|}
\hline \multicolumn{2}{|r|}{ Fagotipagem } & \multicolumn{4}{|c|}{ Cepas de S. aureus } \\
\hline \multirow[b]{2}{*}{ Grupos } & \multirow[b]{2}{*}{ Tipos } & \multirow[b]{2}{*}{ No } & \multirow[b]{2}{*}{$\%$} & \multicolumn{2}{|c|}{$\begin{array}{c}\text { Produtoras de } \\
\text { enterotoxina }\end{array}$} \\
\hline & & & & No & $\%$ \\
\hline I & 29 & 11 & 14,6 & - & - \\
\hline I & 52 & 5 & 6,6 & - & - \\
\hline II & $3 \mathrm{C} / 55 / 71$ & 1 & 1,3 & - & - \\
\hline III & 75 & 1 & 1,3 & - & - \\
\hline III & $45 / 53 / 54 / 75 / 83 \mathrm{~A}$ & 1 & 1,3 & - & - \\
\hline $\mathrm{NC} *$ & $94 / 96$ & 1 & 1,3 & - & 一 \\
\hline Experimental & 88 & 1 & 1,3 & - & - \\
\hline Experimental & $86 / \mathrm{HK} 2$ & 1 & 1,3 & - & - \\
\hline $\mathrm{I} / \mathrm{NC}$ & $52 / 52 \mathrm{~A} / 79 / 80 / 95$ & 2 & 2,6 & - & - \\
\hline $\mathrm{I} / \mathrm{NC}$ & $29 / 52 / 52 \mathrm{~A} / 79 / 80 / 95$ & 2 & 2,6 & - & - \\
\hline I/Extra & $52 / 52 \mathrm{~A} / 79 / 80 / 42 \mathrm{D}$ & 2 & 2,6 & - & - \\
\hline $\mathrm{III} / \mathrm{NC}$ & $6 / 42 \mathrm{E} / 81$ & 2 & 2,6 & - & - \\
\hline $\mathrm{I} / \mathrm{III} / \mathrm{NC}$ & $52 / 42 \mathrm{E} / 54 / 81$ & 1 & 1,3 & - & - \\
\hline $\mathrm{I} / \mathrm{III} / \mathrm{NC}$ & $29 / 52 / 52 \mathrm{~A} / 6 / 42 \mathrm{E} / 54 / 75 / 77 / 81$ & 1 & 1,3 & - & - \\
\hline I/NC/Extra & $52 / 52 \mathrm{~A} / 80 / 95 / 42 \mathrm{D}$ & 2 & 2,6 & - & - \\
\hline I/NC/Extra & $29 / 52 / 52 \mathrm{~A} / 79 / 80 / 95 / 42 \mathrm{D}$ & 1 & 1,3 & - & 一 \\
\hline III/NC/Extra & $42 \mathrm{E} / 53 / 54 / 84 / 81 / 42 \mathrm{D}$ & 1 & 1,3 & - & - \\
\hline \multirow[t]{3}{*}{ III/NC/Extra } & $6 / 42 \mathrm{E} / 47 / 53 / 54 / 84 / 81 / 42 \mathrm{D}$ & 1 & 1,3 & - & - \\
\hline & Não tipáveis & 39 & 51,5 & 9 & 23,1 \\
\hline & Total & 76 & 100,0 & 9 & 11,8 \\
\hline
\end{tabular}

* NC - Não Classificados

foram lisadas por nenhum dos fagos dos conjuntos básico internacional, experimental e extra empregados. As demais cepas foram lisadas pelos fagos utilizados, isoladamente ou em associaçāo.

$\mathrm{Na}$ Tabela 8 encontram-se as 76 cepas de $S$. aureus isoladas, distribuidas segundo a fagotipagem e a sua relação com as 38 amostras positivas e as 21 padarias e confeitarias, das quais foram obtidos tais prom dutos.

\section{DISCUSSAOO}

Conu evidencia a Tabela 1, revelaram-se positivas para S. aureus $38,0 \%$ das 100 amostras de doces examinadas. Este porcentual poderia ser maior se tivesse sido feita a simples verificação da presença de $S$. aureus nesses produtos, por meio de técnicas de enriquecimento 67 . Por estas técnicas a pesquisa de $S$. aureus pode ser realizada a partir de quantidade maior de 
IARIA. S.T. Staphylococcus aureus enterotoxigénico em doces cremosos vendidos em padarias e confeitarias do municipio de São Paulo, Brasil. Rer. Saúde pübl., S. Paulo. 15:321-37, 1981

T A B E L A 8

Cepas de $S$, aureus segundo os grupos de fagos e sua relação com as 38 amostras positivas e as 21 padarias e confeitarias com doces dos quais foi isolada essa bactéria (São Paulo. 1975/1576).

\begin{tabular}{|c|c|c|c|c|c|c|}
\hline \multirow{2}{*}{$\begin{array}{c}\text { S. aureus } \\
\text { correspondente aos } \\
\text { fagos (grupos) }\end{array}$} & \multicolumn{2}{|c|}{ Cepas } & \multicolumn{2}{|c|}{ Doces } & \multicolumn{2}{|c|}{$\begin{array}{l}\text { Padarias } \epsilon \\
\text { Confeitarias }\end{array}$} \\
\hline & No & $\% a$ & No & $\%$ r & $\mathrm{No}$ & $\%$ \\
\hline I & 16 & 21,2 & 7 & 18,4 & 5 & 23.8 \\
\hline II & 1 & 1,3 & 1 & 2,6 & 1 & 4,8 \\
\hline III & 2 & 2,6 & 2 & 5,3 & 2 & 9,5 \\
\hline $\mathrm{NC} *$ & 1 & 1.3 & 1 & 2.6 & 1 & 4,8 \\
\hline Experimental & 2 & 2.6 & 2 & 5,2 & 2 & 9.5 \\
\hline $\mathrm{I} / \mathrm{NC}$ & 4 & 5,2 & $: 3$ & 7,9 & 2 & 9,5 \\
\hline I/Extra & 2 & 2,6 & 2 & 5,3 & 2 & 9.5 \\
\hline III $/ \mathrm{NC}$ & 2 & 2,6 & 1 & 2.6 & 1 & 4,8 \\
\hline $\mathrm{I} / \mathrm{III} / \mathrm{NC}$ & 2 & 2.6 & 1 & 2,6 & 1 & 4.8 \\
\hline $\mathrm{I} / \mathrm{NC} /$ Extra & 8 & 3.9 & 3 & 7,9 & 3 & 14.8 \\
\hline [II/NC/Extra & 2 & 2,6 & 1 & 2.6 & 1 & 4,8 \\
\hline Não tipáveis & 39 & 51.5 & 22 & 57.9 & 16 & 76.2 \\
\hline
\end{tabular}

\footnotetext{
* NC - Não Classificados

a -- para 76 cepas

b - para 38 doces positiros

c - para 21 padarias e confeitarias com amostras positivas
}

material tornando, portanto, também maior a possibilidade de isolamento dessa bactéria. o que náo ocorre quando se empregam processos de contagem. Ainda assim, apesat de ter sido usado un processo de contagem ¿ não de enriquecimento. o percentual de positividade para $S$. aureus observado pode ser considerado alto. Ainda na Tabela 1 , pode-se verificar que $18,4 \%$ das amostras positivas, ou seja, $7,0 \%$ do total examinado continham cepas enteroxigênicas.

Analisando-se a Tabela 2 observa-se que os 38 doces positivos para $S$. aureus foran obtidos de $21(52,5 \%)$ das padarias e confeitarias visitadas e que em um terço destas $(33,3 \%)$ vendiam-se doces con cepas produtoras de enterotoxina estafilocócica. Estas observações revelaram çue a presença de $S$. aureus foi muito freqüente nesses estahelecimentos. Entretanto. é necessário que estas bactérias se multipliquem no alimento até atingirem numeros suficientemente elevados, para que a produçâo de enterotixina seja eficaz em ocasionar manifestações clinicas de intoxicaçāo em seus consumidores:- Segundo Peterson e col.:(1962), para um alimento causar intoxicação alimentar estafilocócica, o numero de S. aureus deve atingir $10^{\circ}$ a $10^{\circ} / \mathrm{g}$ do produto. Em 1966. Donnelly e col.2" (citados por Jay ${ }^{1 ;}, 1973$ ) verificaram que em leite sāo necessários $10 \%$ ou mais $S$. aureus por $\mathrm{ml}$ para haver enterotoxina em quantidade detectável. Hobbs em 1968 (citada por Jay4*. 1973) considera que em alimentos, em geral, o numero de $S$. aureus deve atingir, no minimo, $5 \times 10 \% / g$ para haver produção de enterotoxina suficiente para ocasionar manifestaçōes de intoxicação alimentar.

Gilbert e col.: (1972), examinando alimentos associados a 39 surtos de intoxicaçāo alimentar estafilocócica, obtiveram contagem de $S$. aureus que variaram de 7,5 $\times 10^{\circ}$ até mais de $10 \% / \mathrm{g}$. Um desses surtos foi devido a doce com creme, os quais continham $15 \times 10^{i}$ de $S$. aureus por grama. 
IARIA. S.T. Staphylococcus aureus enterotoxigénico em doces cremosos vendidos em padarias confeitarias do municipio de São Paulo, Brasil, Rev. Saúde públ., S. Paulo, 15:321-37, 1981.

Gilbert 35 (1974) referindo 53 surtos de intoxicação alimentar relatou que os números de $S$. aureus encontrados nos alimentos envolvidos variaram de $1,2 \times 10^{\circ}$ a $10^{\circ}$ ou mais por grama. Entretanto, em 4 destes surtos oscilou de $10^{\circ}$ a $10 \% \mathrm{~g}$.

Segundo Angelotti ${ }^{1}$ (1969) as quantidades de enterotuxina tidas como capazes de ocasionar sintomas de intoxicação alimentar em pessoas sensíveis são meramente especulativas, porquanto tais valores são estimados com base na sensibilidade dos processos de determinação da enterotoxina estafilocócica por métodos de imunodifusão em ágar. Este autor, assim como Casmann e Bennett ${ }^{14}$ (1965), admitem que sejam necessários 1 a $5 \mu \mathrm{g}$ deste produto tóxico para causar manifestaçōes patológicas no homem. Porém Bergdoll s (1973) afirma que a quantidade de enterotoxina requerida para ocasionar sintomas em pessoas acredita-se ser menor que $1 \mu \mathrm{g}$.

De acordo com a Tabela 4 , pode-se verificar que das 100 amostras examinadas, 7 continham $10^{5}$ ou mais $S$. aureus $/ g$; destas, 2 apresentaram-se com cepas produtoras, respectivamente, de enterotoxinas C e D. Em todas as classes que compreendem alimentos com numeros de $S$. aureus entre $5 \times 10$ e $105 / g$ do alimento exclusive, foram constatadas cepas produtoras de enterotoxinas B ou C.

Da Tabela 5 depreende-se uma tendência dos resultados em mostrar relação entre a quantidade de $S$. aureus/g do material analisado e a presença de cepas enterotoxigênicas; entretanto, o número reduzido de ubservações não permite conclusão definitiva a esse respeito. Assim, excluindo-se a classe correspondente às contagens de $S$. aureus de $10^{+}$a $10^{\circ}$ exclusive, as positividades para cepas enterotoxigênicas, com relação às demais classes de $5 \times 10$ a $10^{2}$ até 10 \% ou mais, foram de, respectivamente, $14,2 \%, 15,4 \%, 20,0 \%$ e $100,0 \%$.

Analisando-se a Tabela 6 observa-se que embora as bumbas com creme tenham apresentado alta percentagem $(30,6 \%)$ de anostras contaninadas com $S$. aureus, de nenhuma delas conseguimos isolar cepas enterotoxigênicas dessa bactéria. Por outro lado, bolos e folhados com creme de recheio e/ou de cobertura revelaram-se com o maior porcentual de positividade $(51,4 \%)$. Das 35 amostras deste grupo, $4(11,4 \%)$ foram positivas para cepas produtoras de enterotoxina do tipo $\mathrm{C}$, sendo duas a partir de dois bolos, uma de torta e uma de folhado. Pudins, bombocados e quindins revelaram-se com positividade também alta $(33,3 \%)$, ocupando o segundo lugar, dentre os doces estudados, quanto à presença de $S$. aureus. De duas amostras de pudim foram isoladas cepas produtoras de enterotoxina, respectivamente, dos tipos C e D. A cepa produtora de enterotoxina $D$ foj isolada de uma amostra de pudim coberta com "fios de ovos", revelando contagem de $S$. aureus de $3 \times 10 \% / \mathrm{g}$ do produto. Desta amostra foram isoladas quatro cepas de $S$. aureus, verificando-se que três não eram enterotoxigenas e uma era produtora de enterotoxina do tipo $D$. Admitindo-se que as quatro colônias foram representativas do total de colônias da placa de contagem correspondente, dos $3 \times 10^{\text {i }} \mathrm{S}$. aureus $/ \mathrm{g}$ do produto, $7,6 \times 10 \% / g$ seriam produtores de enterotoxina. Cumpre salientar que alimentos revelando contagem de $S$. aureus de $10^{\circ}$ a $10^{6 / g}$ têm sido responsabilizados por surtos de intoxicação alimentar ${ }^{35}$.

Relativamente às amostras de sonho com creme, observou-se também positividade alta $(30,8 \%)$. De uma das quatro amostras positivas para $S$. aureus isolou-se uma cepa produtora de enterotoxina do tipo $B$.

Os pães doces cobertos com creme foram os que se revelaram com menor positividade para S. aureus. Das quatro amostras examinadas, obtidas de estabelecimentos diferentes, em apenas uma foram constatados 50 S. aureus $/ g$ (Tabela 3). As três amostras restantes foram negativas para esta bactéria.

$\mathrm{Na}$ Inglaterra, estudos realizados $36,37,0: 2$ mostram que há uma predominância de cepas produtoras de enterotoxina do tipo 
IARIA, S.T. Staphylococcus mureus enterotoxigênicc em doces cremosos vendidos em padarias e confeitarias do municipio de São Paulo, Brasil Rev. Saude públ., S. Paulo, 15:321-37, 1981.

A, nos alimentos envolvidos em surtos de intoxicação alimentar estafilocócica, incluindo produtos de confeitaria. Entretanto, Wieneke 6 (1974) constatou que era menos frequiente a produção de enterotoxina dos tipos $A, B, C$ e $E$ por cepas isoladas de alimentos crus como frangos, carne, leite e queijo do tipo "Cheddar", do que entre as obtidas a partir de produtos cozidos. Nestes alimentos era mais freqüente o isolamento de cepas produtoras de enterotoxina do tipo D.

No Brasil, Dellazari e Leitão 25 (1976), em 106 cepas de $S$. aureus enterotoxigenas, isoladas de macarrão de produção comercial, verificaram que $31,1 \%$ eram produtoras de enterotoxina do tipo $A, 12,2 \%$ do $D$, $7,5 \%$ do B e $3,7 \%$ do $E ; 4,5 \%$ das cepas produziram, simultaneamente, enterotoxinas dos tipos A e B. Houve, portanto, predominância de cepas produtoras de enterotoxina do tipo A. No presente estudo, das 76 cepas pesquisadas, $7(9,2 \%)$ mostraram-se enterotoxigenas, das quais $5(71,4 \%)$ produziram enterotoxina do tipo $C$, uma $(14,3 \%)$ do $B$ e uma $(14,3 \%)$ do $D$, predominando, portanto, as produtoras de enterotoxina do tipu C.

Produtos de confeitaria, segundo a literatura a esse respeito, são freqüentemente responsabilizados por surtos de intoxicação alimentar estafilocócica $17,32 .+4,4$.

Em nosso pais, tanto a estrutura quanto os caracteres epidemiológicos de intoxicação alimentar estafilocócica são desconhecidos. dada a falta de dados sobre a ocorrência de surtos dessa doença, adequadamente diagnosticados. Isto deve-se, em parte, à falta de notificação e, nos casos comunicados, a não existência de condições laboratoriais necessárias à realizaçāo do diagnóstico de certeza.

Neste estudo procuramos verificar, também, se havia relação entre os resultados da fagotipagem e a produção de enterotoxina. Analisando-se, porém, a Tabela 7 . observa-se alto porcentual $(51,5 \%)$ de cepas de $S$. aureus não sensiveis a nenhum dos fagos pertencentes ao conjunto básico internacional nem aos fagos experimentais e extras utilizados. Verifica-se, também, que entre as 39 cepas não tipáveis estão incluídas as $9(23,1 \%)$ produtoras de enterotoxina. Ainda na Tabela 7, pode-se observar que $37(48,5 \%)$ cepas foram lisadas por um ou mais fagos. Destas, $35 \quad(94,6 \%)$ foram sensiveis a fagos do conjunto básico internacional sendo-o, algumas vezes, também, aos fagos extras. Apenas duas cepas foram lisadas somente pelos fagos 88 e $88 / \mathrm{HK} 2$, respectivamente. O emprego dos fagos experimentais $86,88,89,90, \mathrm{D} 11$ e HK2 permitiu que somente duas cepas não fossem incluídas entre as não tipáveis. Entretanto, ainda assim, o número de cepas não tipáveis foi muito alto.

Deve-se salientar, por outro lado, que 11 $(14,6 \%)$ cepas foram sensiveis ao fago 29 e $5(6,6 \%)$ ao 52, em ambos os casos isoladamente, sendo estas freqüências as mais altas observadas, excetuando-se a das cepas não tipáveis. Porém, do total de cepas, $16(21,0 \%)$ foram lisadas pelo fago 52 . isoladamente ou em associação, ocorrendo o mesmo em $15(19,7 \%)$ com relação ao 29. Das 37 cepas fagotipáveis, nenhuma delas revelou capacidade produtora de enterotoxina.

No Brasil, Lopes 49 (1972), de 50 cepas de $S$. aureus isoladas de pescado, $66,0 \%$ foram sensiveis aos fagos $52 / 52 \mathrm{~A} / 80$, sendo as mais freqüentes, e $26,0 \%$ ao fago 29 . Em seu estudo, apenas uma cepa não era tipável $(2,0 \%)$ pelos fagos do conjunto básico. Em outra pesquisa, Lopes e col.50 (1973) verificaram que de 60 cepas de $S$. aureus isoladas de produtos cárneos embutidos $30,0 \%$ mostraram-se não sensiveis aos fagos do conjunto básico. Das 42 cepas tipáveis, $18,8 \%$ foram lisadas pelo fago 86 isoladamente e $12,0 \%$ pelos fagos $29 / 52$ / $/ 52 \mathrm{~A} / 80 / 81$.

Analisando-se a Tabela 8 , pode-se depreender que entre as cepas tipáveis de $S$. aureus, houve predominância das que foram lisadas por fagos do grupo I, isoladamente $(21,2 \%)$. Entretanto, considerado-se, tam- 
IARIA, S.T. Staphylococcus aureus enterotoxigènico em doces cremosos vendidos em padarias e confeitarias do município de São Paulo, Brasil, Rev. Saúde públ., S. Paulo, 15:321-37, 1981.

bém, a sua associação com os fagos do grupo $11, \mathrm{NC}$ e extra, esse porcentual se elevou a $35,5 \%$, fração que compreende 27 cepas; foram, também, apreciavelmente frequientes as cepas sensíveis aos fagos do grupo NC, pertencentes ao conjunto básico internacional. Isoladamente, uma cepa $(1,3 \%)$ mostrou relação com fagos deste grupo mas, levando-se em conta as associações com fagos dos grupos 1,111 e extra, o número elevou-se a $14(18,4 \%)$.

De alimentos associados a surtos de intoxicação alimentar isolam-se comumente cepas de $S$. aureus sensiveis a fagos do grupo III $5 t$ ou dos grupos I/III 62,69.

Ainda na Tabela 8 verifica-se que cepas de $S$. aureus, não relacionadas aos fagos empregados foram isoladas de 22 amostras de doces produzidas e vendidas em $16(76,2 \%)$ das 40 padarias e confeitarias. Isso mostra que cepas não tipáveis foram muito freqüentes nos estabelecimentos visitados. Por outro lado, quanto às cepas que se mostraram sensiveis a um ou mais dos fagos empregados, verifica-se que as relacionadas com o grupo I foram mais frequientemente encontradas em doces de grande número das padarias e confeitarias visitadas.

Do ponto de vista epidemiológico os resultados obtidos nesta investigação mostram que, se os alimentos examinados estivessem associados a casos de intoxicação alimentar, seria impossível estabelecer relação com a fonte de sua contaminação, visto que as 9 cepas enterotoxigenas isoladas (Tabela 9) não foram sensiveis a nenhum dos fagos empregados e, das tipáveis, todas se comportaram como cepas não produtoras de enterotoxina. Assim, mesmo que fossem isoladas cepas de $S$. aureus não tipáveis, dos manipuladores desses produtos positivos para cepas enterotoxígenas, não se poderia localizar com certeza a fonte de contaminação, ainda que tais cepas fossem, também, produtoras de enterotoxina estafilocócica. Um resultado dessa natureza poderia, no máximo, sugerir uma relação entre o produto contaminado e a fonte de sua contaminação. E importante salientar que a pre- sente investigação mostra que os doces cremosos ou contendo creme podem veicular $S$. aureus enterotoxígeno, devendo ser um elemento importante na cadeia epidemiológica da intoxicação alimentar estafilocócica em nosso meio. Deve-se considerar, ainda, que estes produtos, após a sua elaboração. são consumidos, obviamente, sem tratamento algum e por pessoas de todas as idades, incluindo crianças, nas quais os processos gastrintestinais são muito sérios, por motivos já bastante conhecidos.

A frequiência de $7,0 \%$ de amostras contendo cepas de $\mathrm{S}$. aureus enterotoxigênicas poderia ser interpretada como baixa. Deve-se levar em conta, porém, que apenas 40 padarias e confeitarias foram visitadas e que cerca de $50,0 \%$ delas vendiam doces cremosos positivos para $S$. aureus e destas $33,3 \%$ com cepas enterotoxigenas, ou seja, $17,5 \%$ do total visitado. Por outro lado, o número desses estabelecimentos na cidade de São Paulo é muito alto, sendo também alto o numero de unidades desses produtos vendidos diariamente.

Do exposto pode-se salientar que medidas de profilaxia da intoxicação alimentar estafilocócica se fazem necessárias, envolvendo a educação sanitária dos que manipulam e comercializam este tipo de alimento, o que se constitui em tarefa dificil de ser desenvolvida.

Dack 22 (1964) recomenda como medida de profiláxia, além da educação sanitária dos manipuladores, a conservação sob refrigeração dos produtos recheados com creme ou reaquecimento desses produtos após o seu preparo, em temperaturas entre $190,6^{\circ} \mathrm{C}$ e $218,3^{\circ} \mathrm{C}$ por $30 \mathrm{~min}$. Segundo esse autor, os produtos reaquecidos mostram após esse tratamento, apenas discretas alteraçōes de aspecto e sabor.

\section{CONCLUSOES}

1. Das 100 amostras de doces examinadas $38,0 \%$ foram positivas para $S$. aureus e $7,0 \%$ continham cepas produtoras de enterotoxina $B, C$ ou $D$. 
IARIA, S.T. Staphylococcus nireus enterotoxigênjco em doces cremosos rendidos em padarias * confeitarias do município de São Paulo. Brasil Rev. Saude públ., S. Paulo, 15:321-37. 1981.

2 Enı alta proporção das 40 padarias e confeitarias visitadas $(52,5 \%)$ comercializavam-se doces contaminados com S. aureus e em $17,5 \%$, doces com cepas produtoras de enterotoxina estafilocócica.

3 Do total de doces examinados, $7,0 \%$ continham $10^{\circ}$ ou mais de $S$. aureus por grama, número tido como limite a partir do qual o alimento pode provocar intoxicação alimentar.

4 Das 38 amostras positivas para $S$. aureus, 5(13,2\%) continham cepas produtoras de enterotoxina estafilocócica do tipo $C$, sendo este o predominante. Uma $(2,6 \%)$ apresentou cepas produtoras de enterotoxina do tipo B e outra $(2,6 \%)$ do tipo $D$.

5. Das 76 cepas de $S$. aureus isoladas, un alto porcentual $(51,5 \%)$ nāo se mostrou sensivel a nenhum dos fagos do conjunto básico internacional nem aos exeperimentais e extras utilizados. Neste grupo de cepas estão incluidas as $9(11,8 \%)$ produtoras de enterotoxina estafilocócica.

b. Entre as cepas fagotipáveis houve predominância das que foram lisadas por fagos do grupo I isoladamente $(21,2 \%)$ ou em associação con fagos de outros grupos $(35,5 \%)$. Em segundo lugar aparecem as cepas sensiveis a fagos do grupo não classificado do conjunto básico internacional ou em associação $(18,4 \%)$.

7. Cepas não tipáveis de $S$. aureus estavam presentes em doces de $76,2 \%$ das padarias e confeitarias em que houve amostras positivas para essa bactéria.

IARIA. S.T. [Enterotoxic Staphylococcus aureus in creamy sweets sold in bakeries in the city of $\mathbf{S}$. Paulo, Brazil\}. Rev. Saúde públ., S. Paulo, 15:321-37. 1981.

ABSTRACT: One hundred samples of creamy sweets were collected from 40 bakeries in the city of $\mathbf{S}$. Paulo (Brazil), for the determination of Staphylococcus aureus counts per gram of food. After morphological and biochemical identification, phagetyping was performed and production of enterotoxin verified. Of the samples collected $38.0 \%$ were positive for Staphylococcus aureus. These samples came from $21(52.5 \%)$ of the 40 bakeries. Of those positive, $7.0 \%$ were positive for enterotoxin, $5.0 \%$ for type C, $1.0 \%$ type B, and $1.0 \%$ type D. Of the 76 strains of Staphylococcus aureus isolated, $39(51.5 \%)$ could not be classified according to known phagetypes. Of the remainder, those lysed by group I phages alone or associated to other groups predominated $(21.2 \%$ and $35.5 \%$ respectively). Strains not classified under known phagetypes were isolated from $76.2 \%$ of positive establishments.

UNITERMS: Staphylococeus aureus. Enterotoxins. Staphylococcal food poisoning.

\section{REFERENCIAS BIBLIOGRAFICAS}

1. ANGELOTTI, R. Staphylococcal intoxications. In: Riemann, H. ed. Food_borne infections and intoxications. New York. Academic Press, 1969. p. 359-93.

2. BAIRD-PARKER, A.C. An improved diagnostic and selective medium for isola- ting coagulase positive staphylococci. $J$. appl. Bact., 25:12-9. 1962.

3. BAIRD-PARKER, A.C. Methods for classifying staphylococci an $I$ micrococci. In Gibbs, B.M. \& Skinner, F.A. Identification methods for microbiologists. London. Academic Press. 1966. p. 59-64. 
IARIA, S.T. Staphylococcus aureus enteroloxigênjco em doces cremosos rendidos em padarias confeitarias do município de São Paulo. Brasil, Rev. Saúde públ., S. Paulo, 15:321-37, 1981

4. BENNETT, R.W. et al. Staphylococcal enterotoxin: a comparative study of serological detection methods. Canad. Inst. Frood Sci. Techn. J., 6:131, 1973.

5. BERGDOLL, M.S. Enterotoxin detection. In: Hobbs, B.C. \& Christian, J.H.B. ed. The microbiological safety of food. London, Academic Press, 1973. p. 287-92.

6. BERGDOLL, M.S. et al. Identification of enterotoxin E. Infect. Immunol., 4:593-5. 1971.

7. BERGDOLL, M.S. et al. Identification of a new enterotoxin as enterotoxin $\mathrm{C}$ J. Bact., 90:1481-5, 1965.

8. BERGDOLL, M.S. et al. The production of staphylococcal enterotoxin by a coagulase-negative microorganism. Bact, Proc., 67:12, 1967.

9. BERGDOLL, M.S. et al. Staphylococcal enterotoxin (identification of a specific precipitating antibody with enterotoxin neutralising property). J. Immunol., $83: 334-8$. 1959 .

10. BLAIR, J.E. \& WILLIAMS, R.E.O. Phage typing of staphylococci. Bull. Wld Hith Org., 24:771-84. 1961.

11. BRACHMAN, P.S. et al. Food poisoning in the USA. In: Hobbs, B.C. \& Christian. J.H.B., ed. The microbiological safety of food. New York. Academic Press. 1973. p. 143-51.

12. BROWN, G.R. \& BROWN, C.A. Sensitization of erytrocytes with staphylococcal enterotoxin by means of tolylene-2,4 dissocyanate for the passive hemaggluti. nation reaction. Bact. Proc., 65:72, 1965.

13. CASMAN, E.P. \& BENNETT, R.W. Culture medium for the production of staphylococcal enterotoxin A. J. Bact., 86:18-23, 1963.

14. CASMAN, E.P. \& BENNETT, R.W. Detection of staphylococcal enterotoxin in food. Appl. Microbiol., 13:181-9, 1965.

15. CASMAN, E.P. et al. Designation of staphylococcal enterotoxin. J. Bact., 85: 715-6, 1963.

16. CASMAN, E.P. et al. Identification of a fourth staphylococcal enterotoxin, enterotoxin D. J. Bact., $94: 1875-82,1967$.
17. CENTER FOR DISEASE CONTROL: Foodborne and waterborne outbreaks; annual summary 1973. Atlant, Ga., Dec 1974.

18. COLLINS, W.S. et al. A rapid solid-phase radioimmunoassay for staphyjococcal $B$ enterotoxin. $J$. Immunol., 108:852-6. 1972.

19. COLLINS, W.S. et al. Rapid solid-phase radioimmunoassay for staphylococcal enterotoxin A. Appl. Microbiol., 25:774-7, 1973.

20. Cotillo Z., L.G. Tentativas de inhibición de la sintese de enterotoxina esta. tilococica por penicilina $y$ estreptomicina. Rev. Saúde públ., S. Paulo, $1: 188-92,1967$.

21. CROWLE, A.J. A simplified micro double-diffusion agar precipitin technique. $J$ Lab. clin. Med., 52:784-7, 1958.

22. DACK, G.M. Food poisoniny. $3 \mathrm{rd}$ ed Chicago. University of Chicago Press, 1964. p. 109-58.

23. DACK, G.M. et al. An outbreak of food polsoning proved to be due to a yellow hemolytic staphylococcus. J. prev. Med. $4: 16^{\prime} 7-15,1930$.

24. DAVISON, E. et al. Attempts to assay the enterotoxin substance produced by staphylococci by parenteral infection of monkeys end kittens. $J$. infect. Dis., 62:219-23, 1938 .

25. DELAZARI, I. \& LEITÃO. M.F.F. Staphylococcus aureus enterotoxigênico em. macarrão. Col. Inst. Tecnol. Alim., 7 . 485-97, 1976.

26. DI SALVO, G.W. Desoxyribonuclease and coagulase activity of micrococci. Med. Techn. Bull., 9:191-6, 1958.

27. DOLMAN, C.E. et al. A new method of detecting Staphylococcus enterotoxin. Canad. publ. Hlth J., 27:489-93, 1936.

28. DONNELLY, C.B. et al. Serological identification of enterotoxigenic staphylococci from cheese. Appl. Microbiol., 15:1382-7. 1967.

29. EVANS, J.B. Studies of staphylococci with special reference to the coagulase-positive types. J. Bact., 55:793-800, 1948.

30. EVANS, J.B. \& NIVEN JR., C.F. A comparative study of known food-poisoning staphylococci and related varieties. J. Bact., 59:545-50. 1950 . 
IARIA, S.T. Staphylococcus aureus enterotoxigênico em doces cremosos vendidos em padarias e confeitarias do município de São Paulo, Brasil. Rev. Saúde públ., S. Paulo, 15:321-37, 1981.

31. EVANS, J.B. et al. Evaluation of the coagulase test in the study of staphy. lococci associated with food-poisoning. J. Bact., $60: 481-4,1950$.

32. FOOD-BORNE DISEASE IN CANADA; Annual summary 1973. (Health Protection Branch, Health and Welfare Canada) Ottawa. 1976.

33. FRIEDMAN, M.E. \& WHITE, J.D. Immunofluorescent demonstration of cell associated staphylococcal enterotoxin $B$. J. Bact., $89: 1155,1965$.

34. GENIGEORGIS, C. \& SADLER, W.W Effect of sodium chloride and $\mathrm{pH}$ on enterotoxin B production J. Bact., 92: 1383-7, 1966.

35. GILBERT, R.J. Staphylococcal food poisoning and botulism. Postgrad. med. J.. $50: 603-11,1974$.

36. GILBERT, R.J, \& WIENEKE, A.A. Staphylococcal too.. poisoning with special reference to the detection of enterotoxin in food. In: Hobbs, B.C. \& Christian, J.H.B., ed. The microbiological safety of food. London. Academic Press, 1973. p. $273-85$

37. GILBERT, R.J. et al. Serological detection of enterotoxin in foods implicated in staphylococcal food poisoning. J. Hyg., London, $70: 755-62,1972$.

38. HALL, H.E. et al. QLiantitative detection of staphylococcal enterotoxin B in food by gel-diffusion methods. Publ. Hlth Rep., 78:1089-98, 1963.

39. HALLANDER, Ft.O. Production of large quantities of enterotoxin $B$ and other toxins on solid media. Acta path. microbiol. scand., 63:299-305, 1965.

40. HOPPER, S.H. Detection of staphylococcal enterotoxin. I. Flotation antigen-antibody system. J. Food Sci., 28:572-7. 1963.

41. HOBBS, B.C. Food poisoning and food hygiene. 3 rd ed. London, Edward Arnold, 1976.

42. IARIA, S.T. et al. Pesquisa de Staphylococcus aureus enterotoxigênico nas fossas nasais de manipuladores de alimentos em hospitais, São Paulo, 1976. Rev. Saúde puibl., S. Paulo, 14:93_100, 1980.
43 INGRAM, M. Bacterial multiplication in pacek witshire bacon. $J$. appl. Bact. $23: 206,1960$.

14. JAY, J.M. Microbiologia moderna de los rtlimentos. Zaragoza, Ed. Acribia, 1973. p. 190-209.

45. JENNINGS, W.E. Food-borne illness. In: Libby, J.A., ed. Meat hygiene. 4 th ed. Philadelphia, Lea \& Febiger, 1975. p. 261-95.

46. JOHNSON, H.M. et al. Enterotoxin B: serological assay in cultures by passive hemagglutination. Appl. Microbiol., 15. 815-8, 1967.

47. JORDAN, E.O. \& Mc BROOM, J. Results of feeding Staphylococcus filtrates to monkeys. Proc. Soc. exp. Med., 29:161-2, 1931.

48. KELLY, F.C. \& DACK, G.M. Experimental Staphylococcus, food poisoning. Amer, $J$. publ. Hlth, 26:1077-82, 1936.

49. LOPES. C.A.M. Contribuição ao estudo da flora bacteriana de sardinha (Sardinella aurita) $e$ de pescada branca (Microdon ancylodon). São Paulo, 1972. [Tese de Doutoramento - Instituto de Ciências Biomédicas da USP].

50. LOPES, C.A.M. et al. Fagotipagem de linhagens de Staphylococcus aureus isola las a partir de produtos cárneos embutidos. Arq. Inst. Biol., $\mathrm{S}$. Paulo. 40:139-42, 1973.

51. MUNCH-PETERSEN, E. Staphylococei in food and food intoxication. A review and an appraisal of phage typing results. J. Food Sci., 28:692-710, 1963.

52. MORRISON. S.M. et al. Stcphylococcu. aureus in domestic animals, Publ. Hlth Rep., 76:673-7, 1961.

53. MORSE, S.A. \& MAH, R.A. Microtiter hemagglutination_inhibition assay for staphylococcal enterotoxin B. Appl. Microbiol., 15:58-61. 1967.

34. PARKER, M.T. \& LAPAGE, S.P. Penicillinase production by Staphylococcus aureus strains from outbreaks of food poisoning. J. clin. Path., 10:313-7. 1957.

55. PETERSON. A. et al. Staphylococci competition. I. Growth of naturally occurring mixed populations in precooked frozen foods during defrost. Appl. Microbiol. 10:16-22. 1962. 
IARIA, S.T. Staphylococcus aureus enterotoxigénico em doces cremosos vendidos em padarias e confeitarias do municipio de São Paulo, Brasil, Rer. Saúde públ., S. Paulo, 15:321-37. 1981

56. READ JR.. R.B. et al. Assay of staphylococcal enterotoxin from cheese. $J$. Dairy Sci., 48:420-4. 1965.

57. READ JR., R.B. et al. In vitro assay of staphylococcal enterotoxin $A$ and $B$ from milk. J. Dairy Sci., 48:411-9, 1965.

58. RIGDON, R.H. Observations on Dolman's test for determining the presence of staphylococcal enterotoxin. Proc. Soc. exp. Biol. Med., 38:82-4. 1938 .

59. ROBINSON, J, \& THATCHER, F.S. Deter mination of staphylococcal enterotoxin by an indirect hemagglutination inhibition procedure, Bact. Proc., 65:72. 1965.

60. SILES-VILLARROEL, M. Contribuigãa ao estudo de venenos de serpentes do yénero Bothrops (B. Jararaca. B. alternatus, B. insularis, B. Jararacissu, B athrox, B. cotiara). São Paulo, 1972 [Tese de Doutoramento - Instituto de Ciências Biomédicas da USP].

61. SILVERMAN, G.J. et al. Microbial analysis of frozen raw and cooked shrimp. Food Techrol,, 15:455-8, 1961.

62. SIMKOVICOVA, M. \& GILBERT, R.J. Serological detection of enterotoxin from food poisoning strains of staphylococcus aureus. J. med. Mucrobiol., 4:19-30, 1971.

63. SMITH, D.T. et al, Los estafilococos. In: Smith. D.T, et al. Microbiologia de Zinsser. 4" ed. Mexico. Ed. Hispano-Americana, 1971. p. 548-76.

64. SOLE-VERNIN, C. Fagotipagem de Staphylococous aureus. Rev, bras. Ort, Rio de Janeiro, 11:31-4, 1976.

65. SPLitTSTOESSER, D.F. et al. Contamination of frozen vegetables by coagulase-positive staphylococci. J. Milk Food Tecnol., 28:149-51. 1965.
66 SUBCOMMITTEE on Taxonomy of Staphylococci and Micrococel. Minutes of First Meeting (5 th-6 th October, 1964). Int Bull. bact. Nomencl., 15:107-8. 1965.

67 THATCHER. F.S. \& CLARK, D. S. Analisis microbiologico de los alimentos. Zaragoza Ed. Acribia. 1973.

68. WADSWORTH, C. A slide microtechnique Ior the analysis of immune precipitate in gel. Int. Arch. Allergy, 10:355-6C 1957.

69 WIENEKE, A.A. Enterotoxin production b: strains of Staphylococcus aureus isolated from foods and human being. $J$ Hyg. Camb., 73:255-62, 1974.

70. WILliAMS, R.E.O. et al. Bacteriophage typing of strains of Staphylococcus aureus from rarious sources. Lancet. $1: 510-4,1953$.

i1. WILsox. D. Pesquisa de Staphylococcus aureus em leite a ser pasteurizado. Rev Suíde públ., S. Paulo, 11:1-11, 1977.

72. WILSON. G.S. \& MILES, A.A. Topley and Wilson's principles of bacteriology and immunity. 5 th ed. London, Edward Arnold Ltd., 1966. p. 746-79.

73. WOOLPERT, O.C. \& DACK. G.M. Relation of gastro-intestinal poison to other toxic $s$.bstances produced by staphylococci $J$. infect. Dis., 52:6-19. 1933.

74. ZELANTE, F. Contribuição para o estudo de Staphylococcus isolados de canais radiculares. São Paulo, 1974. [Tese de Livre-Docência - Instituto de Ciências Biomédicas da USP].

Recebido para publicação em 11/12/1980

A provado para publicação em 11:03/1981 